\title{
The Tradition of the Joint Voice Singing in the Context of the Orient Culture (As an example of Margilan Singing School)
}

\author{
Azizjon Zokirov \\ The State Conservatory of Uzbekistan, Tashkent, Uzbekistan
}

\begin{abstract}
The article deals with musical heritage of some Orient cultures, joint singing as one of the main part of music art from ancient time to nowadays. The measure reflecting live process of national musical art is a performing practice. Makom is the most example of Uzbek classical musical heritage. The art of singing plays considerable role in culture of Uzbek national music. On the basis of classical singing the following singing directions as "Folk singing" (yallachilik), “Classical singing” (mumtoz yallachilik), “Grand Song” (katta ashulachilik) and “Art of Makom” singing forms were formulated and developed. Greatest representatives of Margilan School of singing.
\end{abstract}

Keywords: Orient music, Makom, grand song, joint voice singing, Qavalli

\section{Introduction}

Rich musical heritage of the peoples of the Orient has been meaningful and spiritual abilities to demonstrate that play. It is this approach to the present day has started as a very important factor. Since the ancient times it has been formulated and widely practiced by folk artists and its importance has not diminished as during the process of transmission to the forthcoming generation, it has been enhanced. It is obvious to everyone that folk musical art has been shaped in two major complementary ways being developed traditionally. First of all, these are considered as the examples of the folk and the creation of vocational training-classical approach. The works related to folk musical traditions are distinctive with run-of-the mill and diverse attributes. But, it is worth to mention that this direction demonstrates various characteristics. Because the process of performance is integral part of social life and linked with development measures. Since persistent pursuit of advancement, adaptability to existing period on traditional base is considered as an essential stage of the process of folk music. The second direction of folk is the harvest of vocational music works associated with classic. Any type of classical song or tune should be nourished with measures representing excellence in cultural as well as national world of the nation, musical theory, literal and esthetical aspects. Hence, it is crucial that examples with such features are to claim uniqueness and persistence.

The measure reflecting live process of national musical art is a performing practice. It is certain if the influence of practical performance on creation is as well as major on condition that it's fundamental core of base will be exactly, persistent and straight forward. It will be a mistake if we say that qualities such as comprehensiveness and intensity of Uzbek national musical heritage attribute this tendency. If "Makom" is the 
most sophisticated example of Uzbek classical musical heritage, the existence of genres concerning "Makom" and its development of various types among the people, and the appearance of classical music in the eastern part of the country realize the scope of expansion. If the link with performance reflects a development through the field, simultaneously first, the great Hafiz-singers will become due to it.

\section{Traditions of Uzbek Singing}

The art of singing plays considerable role in culture of Uzbek national music. All genres in music are directly linked with folk-vocal traditions. Perhaps, therefore since past the singing Art of Hafiz-Singers has brought numerous styles of performing and it has got in various aspects of live singing interpretation methods traditions. In addition to this, solo, ensemble and joint-voice unison singing measures have been shaped as the key methods. Throughout the centuries-old practice, due to remarkable contributions made by the crème de la crème, particular genres emerged for each direction and gained popularity among the people.

Amongst provinces of Uzbekistan, Fergana valley has exceptionally outstanding musical performing traditions. The main principles and persistent rules of "Makomot" are perceived as metro rhythmic freedom. Because this measure has been established on the basis of performance traditions relying on "Freedom" or "free performance" concepts and has turned into single feature. Consequently, numerous directions and styles were generated as the singing traditions of Fergana valley linked with classical singing styles. On the basis of Classical singing the following singing directions as "Folk singing” (yallachilik), "Classical singing” (mumtoz yallachilik), "Grand Song” (katta ashulachilik) and "Art of Makom" singing forms were formulated and developed. Each direction by means of the process of singing performance has its own features of genre. In the practical performance this process progressed with interpretation methods, therefore solo, joint voice unison singing and ensemble performance initiated their own source. Nevertheless, joint voice unison singing outstands among all of those reflecting features of both methods.

The main reason behind titling the report "Tradition of the Joint voice Unison Singing and Temporary Culture (As an example of MARGILAN Singing school)" is that Margilan, since the ancient times, has been considered one of the spiritually enlightened and civilized cities. Fergana valley, thus, was entitled as “Hafiz-Singers' homeland”. Singers' attitude towards musical heritage is reflected in their performance methods and the way they demonstrate. In the historical process of development, a number of singing schools and performance methods arose. Most of the singers at performance schools managed to reach excellence and maturity. Continuation of their style by their followers assured that the performance style would create base for advancement and turning into a separate school.

\section{School and Famous Singers}

The names of the first and greatest representatives of Margilan School are: Ashurali (Mahram), Madali Hofiz, Boltaboy Radjabov, Mamatbuva Sattorov, Jurakhon Sultonov, Akbar Haydarov, Saidmuzaffar Azizov, Ma'murdjon Uzoqov, Isokjon Husanov, Musojon Orifjonov, Ibroximjon Isokov, Mamasiddiq Madaliev, Iskandar Kalandarov, Turdiali Sharipov, Koraboy Kodirov, Nuriddinjon Mamajonov, Rustamjon Otaboev. Among the singing traditions of Margilan, generally, in the style of classical Hafiz-Singing Art-joint-voice unison singing has got an exceptional role. It has been perceived as sophisticated and main style of performance. 
The joint-voice unison singing is advanced and gained popularity on the base of "Katta ashula" performance. "Katta Ashula" means "Grand Song". The joint-voice singing was mainly spread among people while singers were performing "Katta Ashula". And the main performing basis of "Katta Ashula" is the joint-voice singing too. According to description of the eldest teachers and inscriptions joint-voice singing originated and initiated from the performance traditions of great singers as Boltahofiz, Mamadbuva Sattorov and Jurakhon Sultonov, Ma’murdjon Uzoqov.

Thus, the joint-voice singing art involves a number of main features of singing:

(1) ability of solo singing;

(2) creative approach to performance;

(3) clear-sightedness;

(4) complementarity feeling the other joint-singer;

(5) ability of improvisation;

(6) ability of demonstration of excellence and high skill.

Tradition of joint-voices singing there was in the music culture of the peoples of the Orient, India, Pakistan, Iran, Afghanistan and the Turkish people performing, the procedure established tradition in its own way. In particular, the leading musical traditions of India and Pakistan "Qavalli" genre can be noted. In art of singing it presents tenderness and uniqueness. As the contemporary art development, the joint-voice unison singing tradition has influenced on other genres features and thus it is sign of nationality. Joint-voices performing art embodies a number of aspects that are important. In Margilan traditions the art of joint-voice singing is illustrated in the example of "Katta ashula" genre. In Uzbek singing art, the joint-voice unison singing is valued for its exclusiveness. Above mentioned performance traditions of singers have been regarded and practiced as model for singers of following generation. As the contemporary art development, the joint-voice unison singing tradition has influenced on other genres features and thus it is sign of nationality. For instance; classical singing art is classical "Yallachilik". As novelty of the direction the joint-voice singing of Jurakhon Sultonov with Ma'murdjon Uzokov. Jurakhon Sultonov and Ma'murdjon Uzokov has implemented a new approach in performing and practiced it. Furthermore, utilizing musical instruments used by "Katta ashula performance", relying on performing style enriched and fixed Katta Ashula to the current time. For example, "Mehnat ahli", “Gulozorim qani”, “Oh, kim raxm aylamas” and “Bo’lmasa”.

This is justification of the statement that classical "yallachilik" traditions served as the origin of this joint-voice unison singing technique. Therefore a number of songs with distinctive characters take place in performance repertoire. The people who were influenced by the school could carry on joint-voice singing traditions: Rasulkori Mamadaliev and Kamoliddin Khamrokulov; Hakimjon Fayziev and Orifkhon Khotamov; Isoqjon Husanov; Musajon Orifjonov and Ibrohimjon Isoqov; Odiljon Yusupov and Nabijon Saidnazarov; Fattohkhon Mamadaliev and Yoldashboy Kiyikov; Turdali Sharipov and Koraboy Kodirov; Nuriddinjon Mamajonov, Rustamjon Otaboev.

\section{Conclusion}

This tradition has influence on contemporary process. Certainly, advancement of the art of singing is effected and shaped by period and epoch. Nowadays singers who are contributing in persistent development of 
joint-voice singing are: Makhmudjon Yoldoshev and Makhmudjon Tojiboev; Ismoildjon and Isroildjon Vahabov; Beknazar Dostmuradov and Abdunabi Ibrohimov, Soyibdjon Niyozov; Gofur and Gulom Eshdjonov; Muhsin and Yakhyo Muminov; Ochilbek Matchonov and Khurmat Sobirov; Elmurad Akhmedov and Furkat Ashuraliev. Each of them is continuing this unique method of performance and contributing to the development of contemporary art. In the end XX and beginning XXI centuries, the music art has improved and experienced remarkable growth through as various performance methods have gained popularity. It is known to all that the basis of development of music genres is demand of social life. However, the classical music is a rich, spiritual heritage our nation and its practical performance has always possessed attributes such as comprehensiveness and meaningfulness. That is why studying, researching and introducing, the works of preeminent representatives, passing it to the following generation is becoming permanent tradition of musicologists.

\section{References}

Akbarov, I. (1961). Uzbek folk music. Questions musical culture of Uzbekistan. Tashkent: Uzbekistan Art Literature.

Abdullayev, R. (2005). Masterpieces of central Asia. Tashkent: San’at Magazine Press.

Ibrokhimov, O. (1994). Uzbek folk music (Vol. 1). Tashkent: Ibn Sino.

Karamatov, F. (1961). The main features of the musical structure of Uzbek folk songs. Questions of musical culture of Uzbekistan. Tashkent: Uzbekistan Art Literature.

Mamadjanova, E. (2016). Tradition music of the Uzbeks. Tashkent: Extremum Press.

Mamadjanova, E. (2011). Uzbek “Makoms” in the 21st Century. Journal of Literature and Art studies, 1(1), 31-36.

Vyzgo, T. K. (1972). On the question of the study of Makoms. History and modern times. Problems of musical culture of the Uzbekistan, Turkmenistan and Tajikistan. Moscow: Music.

Zokirov, A. (2016). Joint singing the context of the tradition of modern culture (on example of Margilon performing school). Actual problems of contemporary art studies of Uzbekistan. Tashkent: San'at Art Journal Publishing. 